Research Article

\title{
English Listening Teaching Model in Flipped Classroom Based on Artificial Intelligence Fusion Control Algorithm
}

\author{
Bo Hu (iD) \\ Foreign Language Teaching Depertment, Shenyang Medical College, Shenyang 110034, Liaoning, China \\ Correspondence should be addressed to Bo Hu; hubo@symc.edu.cn
}

Received 26 August 2021; Revised 17 September 2021; Accepted 23 September 2021; Published 14 October 2021

Academic Editor: Sang-Bing Tsai

Copyright (c) 2021 Bo Hu. This is an open access article distributed under the Creative Commons Attribution License, which permits unrestricted use, distribution, and reproduction in any medium, provided the original work is properly cited.

\begin{abstract}
In our contemporary life, various information technologies are changing our lives, and the development of information technology has also provided a certain degree of convenience for the development of education. Now, every country attaches great importance to the development of the informatization of education. This article aims to study how to apply artificial intelligence content and control algorithms to the English listening mode of a flipped classroom. The main purpose of the article is how to make the flipped classroom more intelligent, enrich the content of the classroom, and devote itself to improving children's learning efficiency. This article proposes the application of the PSO algorithm in the flipped classroom to help students learn more intelligently and conveniently in this mode of teaching. They can help children improve their academic performance faster and learn more efficiently. The experimental results of this article show that nearly $65.63 \%$ of students are familiar with the teaching method of using animation video to train English listening, and nearly $70 \%$ of students are very willing to use this teaching method to learn; using more artificial intelligence fusion control algorithms for us, this teaching mode is used for some simplification and assistance. The average test score of the experimental class (82.95 points) is higher than the posttest score of the control class (79.9 points), the excellence rate of the experimental class is $38 \%$, the pass rate is $100 \%$, and the control class has an excellent rate of $32 \%$ in the posttest score. The passing rate was $86.7 \%$. Further analysis shows that, in the posttest scores of the experimental class, the excellent rate and the passing rate have increased, respectively. After the test, the scores of the students in the experimental class have improved greatly compared with the control class. The overall performance of the students has improved significantly.
\end{abstract}

\section{Introduction}

1.1. Background. In recent years, China's artificial intelligence has developed rapidly. With the continuous development of the digital economy in recent years, artificial intelligence has developed rapidly and is deeply integrated into various application scenarios' industry [1]. It has gradually become an important technology to promote economic innovation and growth. The level of artificial intelligence is based on machine learning. In addition to advanced algorithms and computing capabilities, big data is the key to machine learning. Big data can help; the richer and more complete the training data, the higher the accuracy of machine recognition, so big data will become the real capital of enterprises. Analysts believe that big data is the food for the advancement of artificial intelligence. It is an important foundation for building artificial intelligence through the learning of large amounts of data. The judgment and processing capabilities of machines will continue to improve, and the level and some excellent control algorithms will continue to be improved and optimized and use the information for organized expression. The application of modern teaching technology in English teaching is an important way to achieve the goal of the course: how to use modern education technology in the process to cultivate student autonomy and further fully reflect the leading role of teachers in listening. The origin of the flipped classroom model is that, in the past, foreign teachers were unable to attend every class because students were unable to attend the class. Later, the teacher came up with this method, and slowly, its application became more and more widely spread to the country and it is still being optimized middle. 
Traditional English listening teaching uses the teacher to play tapes for us to listen to and then select the answers we heard and then come to the correct answers after playing. This kind of teaching method cannot better raise the children's interest and will lead many children. They are severely biased.

1.2. Significance. The rapid growth of flipped classrooms in China is because the advanced development of modern information technology has changed the educational environment and provided an external foundation for new teaching models. At the same time, it has advantages that traditional teaching models cannot match. First of all, the inverted classroom subverts the traditional model of teachers' classroom teaching and internalization of knowledge through practice and after-school work. "With the support of modern information technology, the transfer of knowledge can be completed after class, and the internalization of knowledge can be completed in the classroom with the help of teachers and students." In the case of limited time and teachers, alternate classrooms can help ensure that the extension of student learning time and internalization time can better accomplish the teaching goals and the implementation of an "effective classroom." Practice English listening: for the parts that you do not understand, you can practice repeatedly at your own pace until you understand it. In the case of artificial intelligence fusion algorithms, this distorted sequence will be smarter and more convenient for us to achieve changes in learning. Through this teaching method, we can understand the learning situation and learning effects of students, so that we can take corresponding countermeasures in time.

1.3. Related Work. After reading a large number of related documents, we found that, with the development of the information age, the places and sources for children to learn are not only in the school classroom, but now teaching can be achieved in various places. In Liu's research, their team analyzed the current situation of IT English teaching and analyzed the problems existing in the teaching process. Based on the above ideas, the SPOC platform is used to build an IT-to-English classroom teaching model, that is, by setting course goals, learning for the class in advance, selecting high-quality classes, collecting learning information, uploading related resources, and preparing complete teaching design for teachers and design specifics. There should be a teaching process of the teaching unit to construct a teaching quality evaluation model. Thus, the results of the evaluation of IT English flipped classroom teaching quality can be obtained, and the teaching quality can be further improved. But in their experimental research, they did not consider those classes with poor academic performance to conducting the same research, so I think it is a bit too onesided to select experimental subjects. Even if students with higher academic performance are required to learn IT English, the experimental objects in this part are indispensable [2]. In Jia's research, he proposed the use of the combination of the Internet and artificial intelligence to analyze the hybrid teaching mode of Internet teaching based on SPOC+ and WeChat Rain Classroom. Based on the analysis results, they novelly proposed a hybrid English teaching model based on such platforms to reveal the combination of the Internet and artificial intelligence. Although their research is very forward-looking, there are still many technical problems that need to be resolved [3]. In Bicen and Beheshti's research, their team proposed exploring "students' views on infographics," "students' views on the FCII learning environment," and "students' academic achievement level." The result is that, compared with the control group, the motivation of the experimental group students is more likely to be triggered by the participation and comprehensiveness of the flipped classroom teaching infographic, which means that they can more easily absorb concepts and remember information faster and become more confident in the educational process. However, there are still many problems in the article, and the consideration of the problems in the experiment is not very comprehensive [4]. In Chen's research, their team proposed that the flipped classroom is a new teaching method that deliberately flips the traditional teacher-centered classroom into a studentcentered one, and in their research, they found that this method is effective for children. Our interest in learning has improved a lot. But their research has no actual data to support it, and there are certain flaws. But in their experiments, they did not have actual data to support the children's real grade changes. They just made judgments based on the children's state during class, which is not rigorous [5]. In Chan et al.'s research, their team introduced the teaching innovation and experience jointly developed by the three MOOCs with the theme of "Discrete Optimization Problem Modeling and Solving" by the two universities. In short, MOOC has a fable-based learning method, which is a problem-based learning form encapsulated in a coherent storyline. Although their research is very forward-looking, science and technology are not in place. Research needs to be further strengthened [6]. In Feng's research, they started from the actual situation of college English branch course teaching, applied the model to college English teaching, put forward the concept of introducing MOOC-based college English flipped classroom into English courses, and used empirical research methods. There is a quantitative research perspective on college English teaching effects based on the MOOC flipped classroom model. Although the experimental results of their research have achieved good results, there are still some influencing factors that have not been eliminated during the experiment, and the experimental results obtained are still not rigorous [7]. In Yu and Peng's research, they proposed constructing an English teaching reform model based on artificial intelligence algorithms. In addition, based on the FISST multitarget tracking method, the article first models the target state and measurement as RFS and then uses the Bayesian filtering method to recursively calculate the target posterior PDF, which can truly estimate the number and state of the target and make up for the shortcomings of traditional tracking methods. The system proposed in the article can be applied to online English teaching. Through this system, teachers can achieve 
one-to-one matching of students, identify the status of students in time, and give corresponding English teaching methods for different students. Some theoretical algorithms of the article's research are relatively simple and have no depth, but the results obtained from the experiment are of great practical value [8].

1.4. Innovation. Based on the analysis of the survey results, learners' learning level, learners' attitudes toward learning English, and listening learning in the flipped classroom model based on artificial intelligence fusion algorithms, learners' learning motivation, learners' self-learning capabilities, etc, and then, through interviews with teachers, the current status and problems of English listening teaching are analyzed, and the course objectives and content are analyzed. On this basis, combined with previous research results and the existing school reality, we construct a teaching model suitable for primary school English listening courses, use the panoramic classroom as a platform for flipped classrooms, use the model to carry out two-class experimental research on primary school English listening courses, and finally verify the design effect of the model. Its purpose is to help students explore the English listening mode that suits them [9].

\section{Related Technologies and Methods}

2.1. Artificial Intelligence Fusion Control Algorithm. The AI artificial intelligence control algorithm is the improvement and maintenance of the PID algorithm, adding the rules of the fuzzy control algorithm and the control of the given value; the power setting is added to the change. Intelligent control is an automatic control technology that can autonomously drive intelligent machines to achieve control goals without human intervention. For many complex systems, it is difficult to establish effective mathematical models and use conventional control theories to perform quantitative calculations and analysis, and a control method that combines quantitative and qualitative methods must be adopted. When the error is large, the fuzzy algorithm is used to make full adjustments to completely eliminate the PID saturation effect and the manual adjustment of skilled workers. When the error tends to be small, the improved PID algorithm is used to control the output, and the control parameters are controlled by the characteristic description of the controlled object, a set of parameters (MPT) can define both PID parameters and fuzzy control parameters. The control accuracy is high. For unstable nonlinear and complex control objects, the system is equipped with adjustable regulation rules, which can further accelerate the response speed and improve the control quality. System selfemployed experts are defined in the system, which can make the determination of system control parameters simple and improve accuracy $[10,11]$. Therefore, the introduction of the self-regulating system not only simplifies complex tasks and saves debugging time but also improves the adjustment quality of the control system. Correspondingly, in our English listening mode learning state, we can solve technical problems more intelligently and reasonably, and we can also learn in a more interesting and intelligent environment, which can greatly increase students' enthusiasm for learning. The structure diagram of the artificial intelligence fusion control algorithm is shown in Figure 1.

2.2. Flipped Classroom. Flipped classroom refers to readjusting the time inside and outside the classroom and transferring the decision-making power of learning from teachers to students. Teachers no longer take up class time to teach information. This information requires students to complete self-study before class. They can watch video lectures, read e-books with enhanced functions, and discuss with other students on the Internet, at any time to check the required materials. After class, students independently plan the learning content, learning rhythm, and style and way of presenting knowledge. Teachers use teaching methods and collaborative methods to meet the needs of students and promote their personalized learning. The goal is to let students get more real learning through practice. The flipped classroom model is part of the big education movement. It overlaps in meaning with blended learning, inquiry learning, and other teaching methods and tools. They are all designed to make learning more flexible and active and to make students more engaged. In the Internet age, students learn a wealth of online courses through the Internet and do not have to go to school to be taught by teachers.

In traditional English listening courses, teachers play audio materials. Students listen several times and complete related exercises. Then, the teacher evaluates checks and explains the results of students' listening according to the answers. Compared with the traditional English listening teaching and the flipped classroom model, the children will be more serious under the traditional mode. The flipped classroom cannot determine the children's learning status, so it is more determined by the children's consciousness. Compared with the traditional English teaching method, the transition to teaching is a new teaching method combining online and offline, which is more humane and personalized and pays more attention to the evaluation of the learning process and the acquisition of knowledge, which is more conducive to students' independent learning ability, cultivation of independent thinking ability, decision-making ability, and teamwork ability [12]. The flipped classroom is based on our real-life video teaching and corresponding multimedia collections, through this way to present a classroom to the children. In the past, teaching was changed to independent online learning before the classroom. In the classroom, the teachers taught intensively and all the staff participated in the interaction. Students work together to complete a series of different tasks and listening activities. After class, students internalize, integrate, and improve the new online teaching methods; the flipped classroom mode is shown in Figure 2.

Our model provides students with learning planning before, during, and after class. Before class, students can log in to the system to obtain the corresponding learning materials and make sufficient preclass preparations. We can 


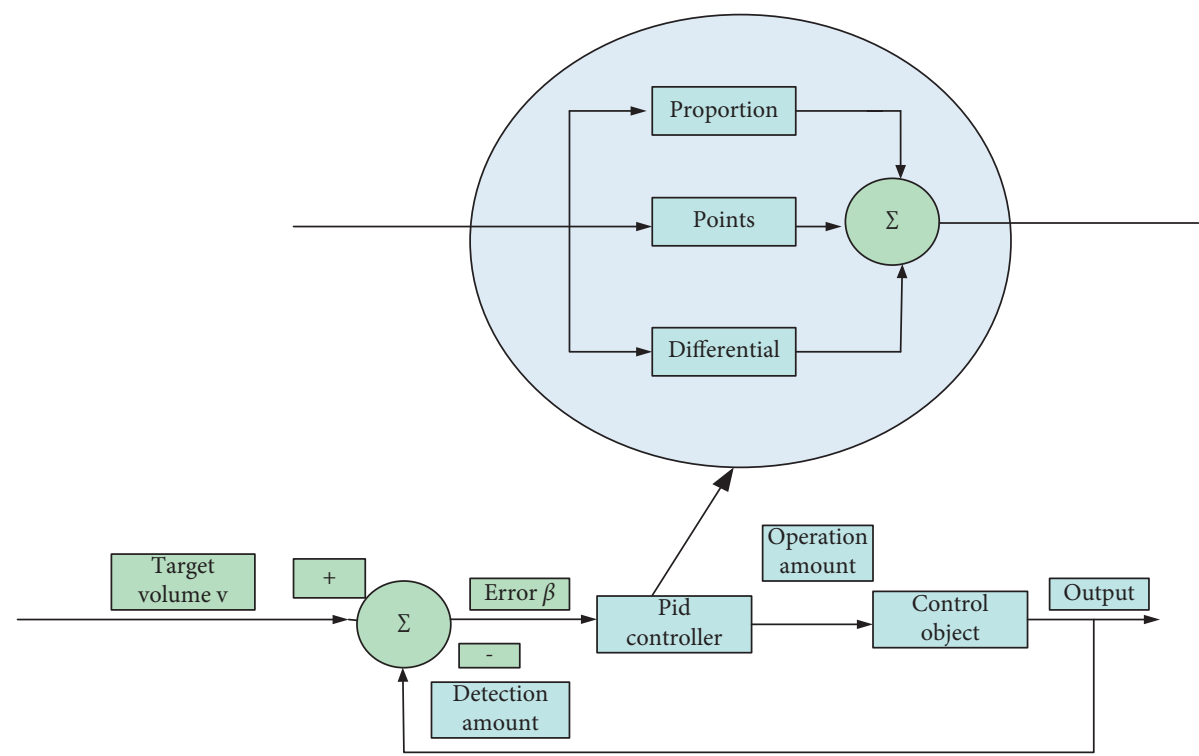

FIGURE 1: Schematic diagram of artificial intelligence fusion control algorithm structure.

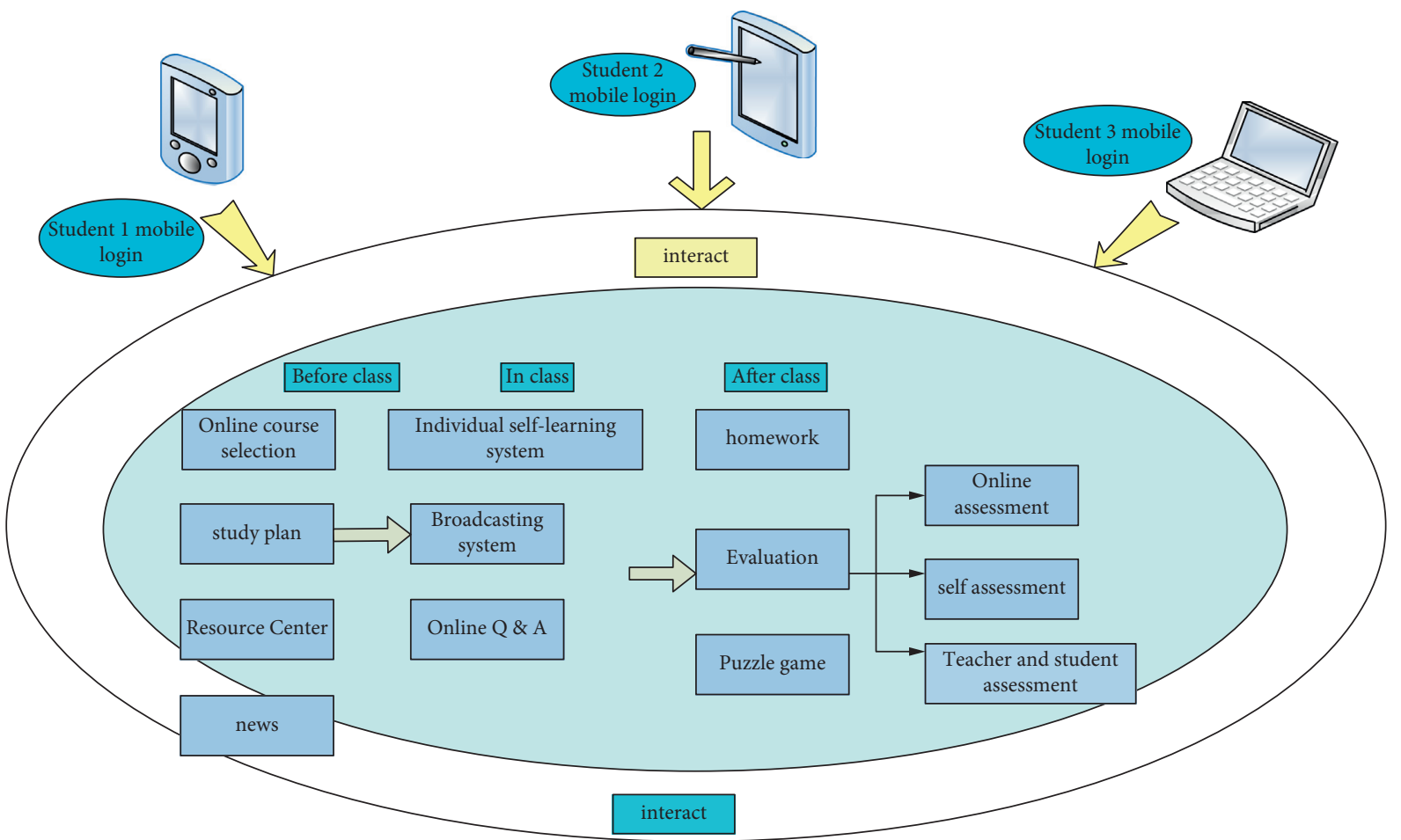

FIGURE 2: Flipped classroom mode.

also choose according to our hobbies. Curriculum and interest are the child's first teacher and will also provide children with some news at home and abroad so that children can learn about real-time news [13]. In the classroom, children do not need to carry heavy school bags to school. They can obtain the corresponding information based on mobile devices. When they encounter problems, they can ask teachers and classmates for help online at any time, which can help children online. Q\&A, after class, children no longer have to worry about homework and forgetting the trouble. Our homework can be submitted anywhere. The premise is that there is a network. Some homework can be controlled by the teacher through the system. Students answer and fill in online, and this can provide timely feedback to students and teachers on the evaluation results, so that they can recognize their shortcomings and strengths in a timely manner, deepen the impression of the learning content, and provide educational learning. Games can allow students to increase their knowledge and improve their learning skills in games. The 
most important thing is that they can learn happily [14]. When encountering a class that some students have dropped because they did not attend the class in time, they can watch the corresponding video according to the class they have dropped after class. According to the statistics of relevant qualitative research literature, it can be inferred that the flipped classroom model is shown in Table 1.

From Table 1, we can see that the literature in this area ranges from 96 to 215. There are more and more studies in this area, which shows that scholars in our country are slowly paying attention to this aspect. From Table 1, we can see that although China's research on flipped classrooms is relatively late, since about 2013, domestic research on flipped classrooms has shown rapid development. Among them, the number of master's thesis literature and core journal CSSCI literature has gradually increased. In contrast, there are relatively few doctoral dissertations on the research on flipped classrooms. Generally speaking, after the research on flipped classrooms has developed from abroad, it has caused an upsurge in China. The research on flipped classrooms in China is at a rapid pace. At the initial stage of development, there are not many studies on flipped classrooms. The most analyzed case is the use of flipped classrooms, which is to analyze what kind of response this teaching mode will have to students, whether it will promote their learning, or whether it gives a bad influence [15]. This is a new type of teaching mode that is superior to artificial intelligence and complex algorithms. The schematic diagram of the flipped classroom mode is shown in Figure 3. The advancement of society has promoted the vigorous development of artificial intelligence technology, so its impact has become more and more important. Due to the emergence of artificial intelligence technology, flipped classrooms have become more and more convenient and efficient. Based on this realistic basis, the author uses artificial intelligence products of the popularization in learning, taking the oral and training of learning English as an example, and then expounding the further application of artificial intelligence in English learning.

In the traditional sense, English listening teaching is that teachers use listening tapes to listen to you and then answer the correct answers. However, the knowledge obtained in this way is also passive. When many students are not interested in English listening, they bring some differences. They will lose interest in English listening and lead to poor English performance. This teaching model has many disadvantages. When we first came into contact with English, it is more about exploring new things. The driving force for us to move forward is that we need to find something that children are interested in. Only in this way can we bring help to students in learning. The disadvantages of the traditional classroom are obvious. After so many years of scientific and technological development, the application of various technologies in teaching is just to better help our children learn better. Under the optimization of various mobile devices and communication systems, children are brought with a more optimized, intelligent, and convenient learning mode [16]. The specific representation is shown in Figure 4.
TABLE 1: Qualitative research literature data.

\begin{tabular}{lcc}
\hline Qualitative research & $\begin{array}{c}\text { Number of } \\
\text { articles }\end{array}$ & Percentage \\
\hline Theoretical research on teaching & 215 & 27.7 \\
mode & 145 & 18.7 \\
Teaching model design & 221 & 28.5 \\
Case application analysis & 99 & 12.8 \\
Technology and platform & 96 & 12.4 \\
Effect evaluation & 776 & 100.0 \\
Total & & \\
\hline
\end{tabular}

As shown in Figure 5, the principle of the pyramid is to summarize a piece of knowledge and system that everyone knows. It is a good tool and concept. The basic structure of the pyramid is as follows: clear central idea, conclusion first, unify the above, categorize and group, and logically advance (first important, then second, overall first, a detail first, conclusion first, cause first, result first, and process first). The application of the learning pyramid theory to the design of the flipped classroom teaching model is mainly reflected in the fact that students learn actively through video animation before class. The form of video animation plays a demonstrative role, which can attract students' attention and high interest in learning and enable students to master more learning content that has changed the current situation of teachers teaching and students passively learning in traditional classrooms. In the course of the class, teachers develop task-oriented teaching methods that focus on real situations and focus on connecting students' learning with real life. Students complete learning tasks together through group discussion and cooperation, which embodies the learning method of active learning in the pyramid theory, pays attention to practice, and raises the retention rate of students' learning content [17].

2.3. Intelligent Control Algorithm. PSO is an evolutionary computing technology based on swarm intelligent control methods, which solves the global optimal solution of iterative optimization problems. The algorithm principle is simple. Compared with genetic algorithms, there are no complex functions such as hybridization and mutation. They are just particles searching for the best particles in the solution space. Compared with other evolutionary algorithms, they have the advantage of being easy to apply and do not require complex models to solve optimization problems. The field of evolutionary computing has been proposed since [18]. As shown in Table 2, according to the number of commonly used search libraries, it can be seen that a large number of libraries and research results have emerged in a short period of more than ten years. It can be clearly seen in Table 2 that, in ten years, the proportion has gone from $3.20 \%$ to $19.60 \%$. We explain that this aspect has gradually become familiar to people.

When the signal propagates in free space and has an unobstructed straight path, the following formula can be used to calculate the distance $R$ between the transmitting 


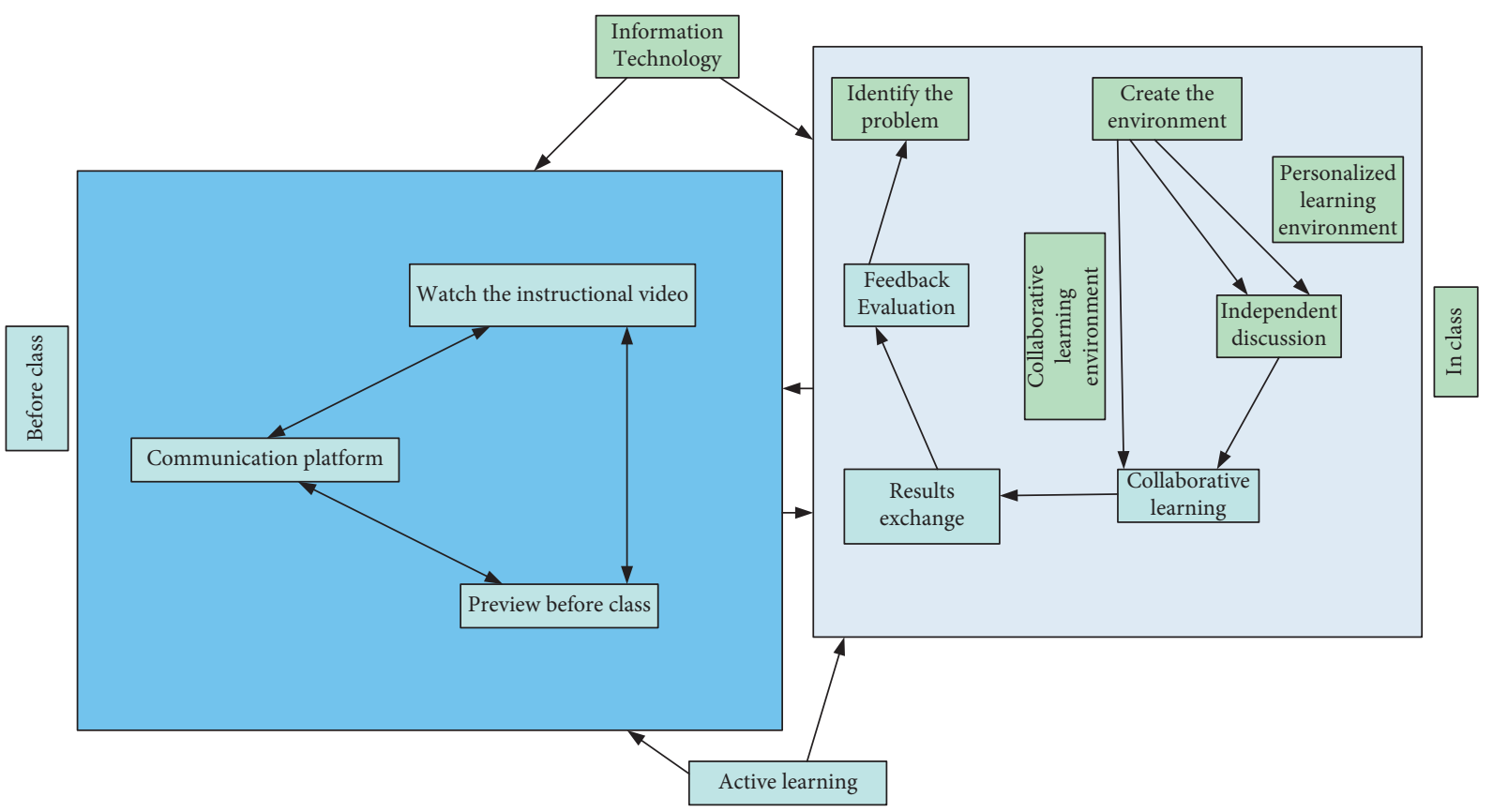

FigURE 3: Schematic diagram of a flipped classroom.

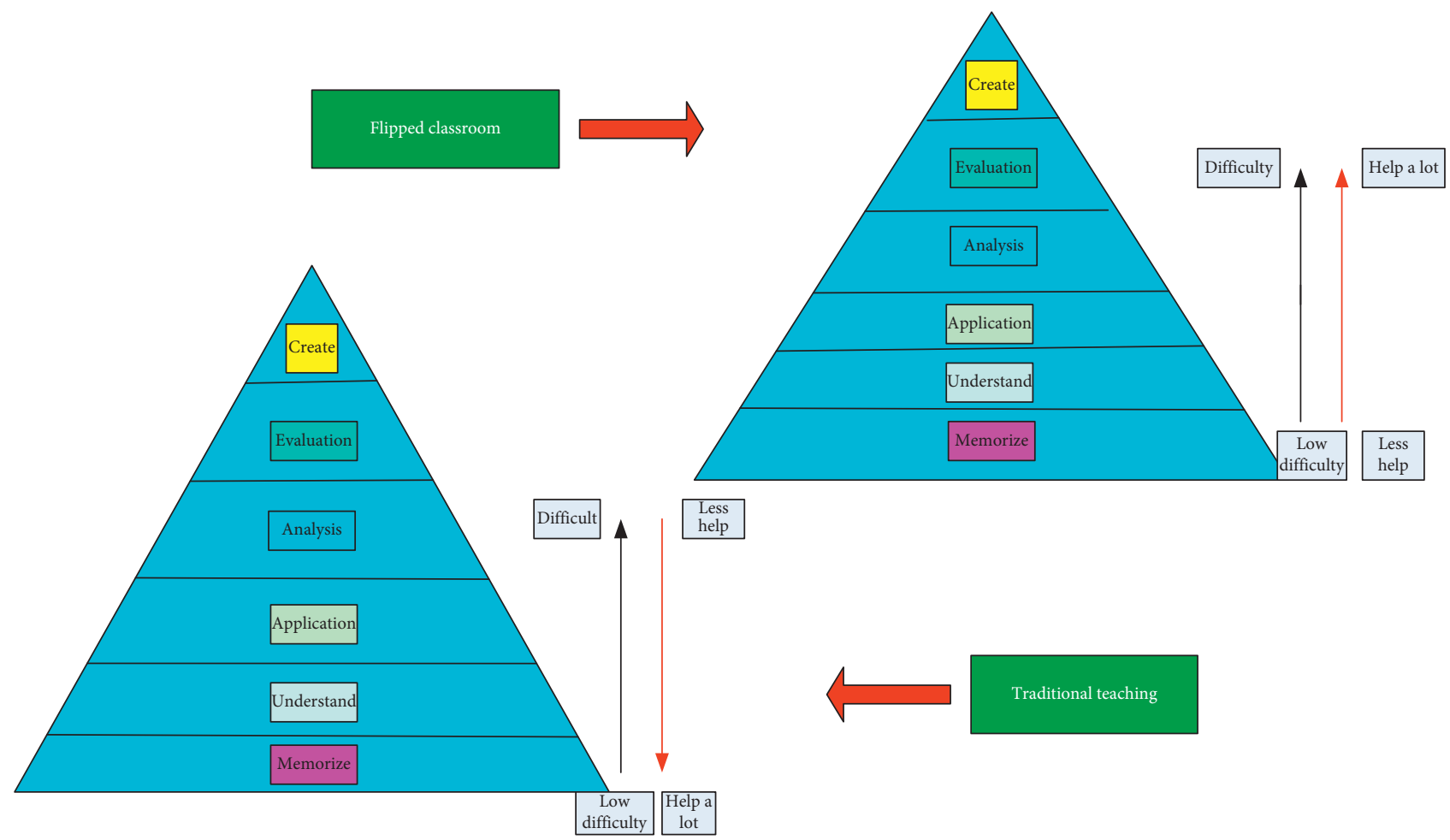

Figure 4: Comparison of a flipped classroom and a traditional classroom.

node and the receiving node after the measurement data is obtained:

$$
p(r)=\frac{p_{k} G_{K} \beta^{2}}{(4 \pi)^{2} r^{2}}
$$

where $P_{K}$ is the power of the transmitter, $p_{r}$ is the received power at the distance $r, \mathrm{r}$ is the distance, and $\beta$ is the wavelength, and the unit is the meter. $G_{\mathrm{t}}$ and $G_{r}$ are the transmitting antenna and the receiving antenna, respectively. With this, we can calculate the distance between the 


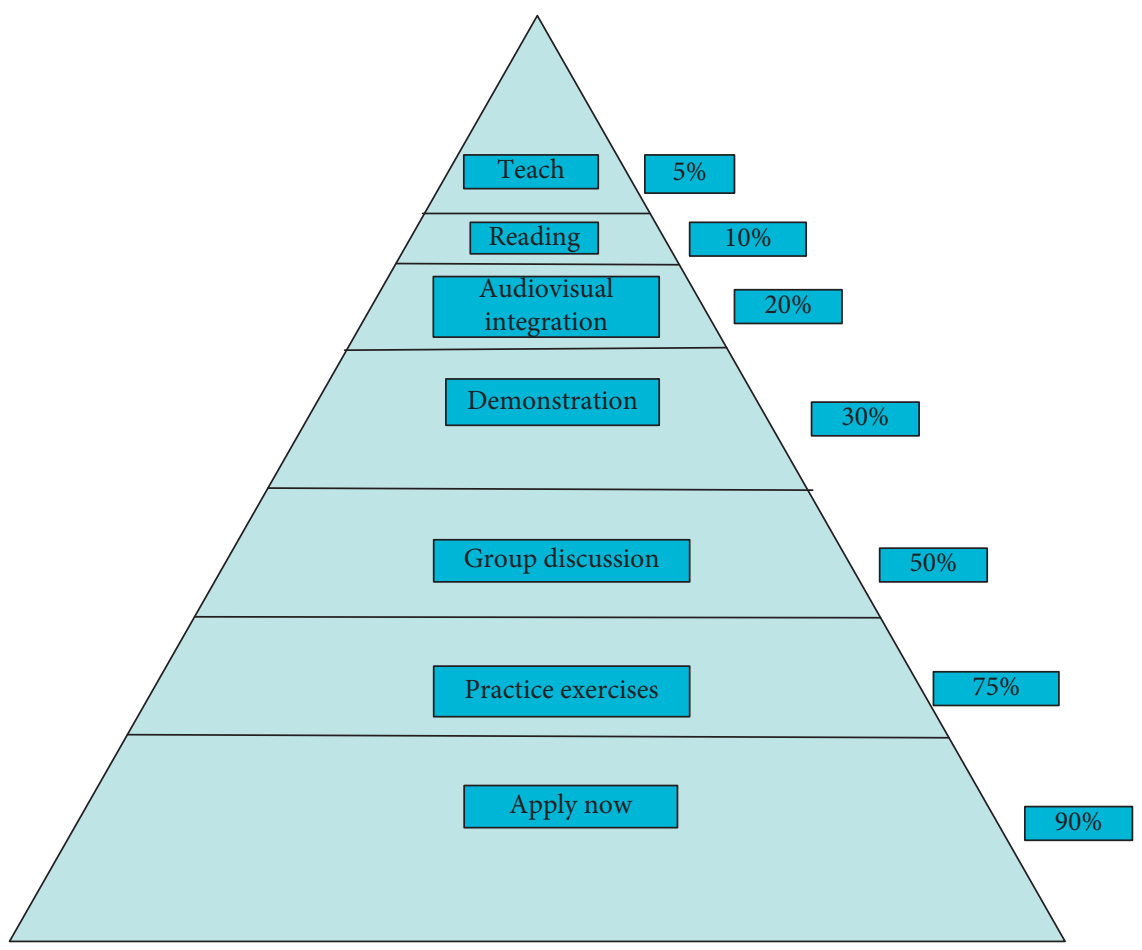

FIgure 5: Pyramid theory.

TABLE 2: Data statistics of particle swarm optimization algorithm in the literature library.

\begin{tabular}{lcc}
\hline Publication year & Records & Percentage \\
\hline 2008 & 300 & 3.20 \\
2009 & 400 & 6.20 \\
2010 & 445 & 7.10 \\
2011 & 523 & 7.50 \\
2012 & 625 & 8.60 \\
2013 & 800 & 9 \\
2014 & 654 & 9.50 \\
2015 & 911 & 10.23 \\
2016 & 240 & 15.66 \\
2017 & 1318 & 18.66 \\
2018 & 1097 & 19.60 \\
\hline
\end{tabular}

transmitting point and the receiving point through a certain calculation.

PSO is an evolutionary computing technology based on swarm intelligent control methods, which solves the global optimal solution of iterative optimization problems. The algorithm principle is simple. Compared with a genetic algorithm, there are no complex functions such as hybridization and mutation. The PSO algorithm has been widely used, but there are also many problems. In order to solve these problems, in order to strengthen the searchability and convergence of PSO, some predecessors have introduced $\omega$ in the formula. The research by Shi and Eberhart shows that when $\omega$ is small, it narrows the network search range of the algorithm, and the powerful local search ability can improve the search accuracy. Balancing search accuracy and convergence speed is the focus of particle swarm optimization [19]. The types of linearly decreasing inertia weights are

$$
v=v_{\max }-\frac{v_{\max }-v_{\min }}{t_{\max }} \times t .
$$

In the above formula, $v_{\max }$ is the maximum value of inertia weight, $v_{\min }$ is the minimum value of inertia weight, $t_{\max }$ is the maximum number of iterations, and $t$ is the current number of iterations. The linear inertia weight is globally optimized in the early stage of the particle swarm, and a local search is performed after the approximate position of the optimal solution is found, which effectively improves the convergence speed and accuracy at the same time. However, when the linearly decreasing weight solves complex problems, it is easy to ignore the population characteristics, the convergence speed slows down, the optimal solution cannot be found, and it is easy to fall into the local optimum. Therefore, in order to balance the global search and the local search and solve the local optimal problem, this paper proposes a nonlinear adaptive inertia weight formula:

$$
v(k)= \begin{cases}v_{\max }-\frac{v_{\max }-(1 / 2) v_{\min }}{(1 / 2) t_{\max }} \cdot k, & k \leq \frac{1}{2} t_{\max }, \\ \left(\frac{1}{2} v_{\max }-v_{\min }\right) \cdot e^{-\left(k-(1 / 2) t_{\max }\right)}+v_{\min }, & k>\frac{1}{2} t_{\max } .\end{cases}
$$

In the above formula, $v_{\max }$ is the maximum value of inertia weight, $v_{\min }$ is the minimum value of inertia weight, and $t_{\max }$ is the maximum number of iterations, which is the 
current number of iterations. In the algorithm search process, the inertia weight of the particle swarm decreases linearly in the early stage $\left(\mathrm{k} \leq(1 / 2) t_{\max }\right)$, and the particle swarm can often find the approximate position of the optimal solution quickly, which can prevent the particle swarm from falling into the local optimum in the early stage; in the late stage of the particle swarm $\left(\mathrm{k}>(1 / 2) t_{\max }\right)$, the inertia weight decreases exponentially, which improves the search accuracy of the particle swarm to find the optimal solution more accurately. The improved inertia weight can adaptively change nonlinearly during the optimization process of the particle swarm. The high-speed optimization of the particle swarm in the early stage improves the convergence speed and, at the same time, improves the search accuracy of the network in the later stage and avoids the particle swarm from falling into the local optimum.

In the process of algorithm optimization, the initial stage should focus on global optimization, focusing on selflearning ability; in the later stage, the particle optimization range should be narrowed to quickly approach the global optimal, focusing on social learning ability [20]. The value of the learning factor $c_{1}$ first becomes larger and then smaller, and the value of the learning factor $c_{2}$ first becomes smaller and then larger. Based on this improved method to search for the global optimum of the network, improve the convergence speed of the algorithm, prevent the algorithm from falling into local freedom, and use the cosine algorithm to improve the learning factor,

$$
\begin{aligned}
& c_{1}=\left(j_{1}-j_{2}\right) * \cos \left(\frac{\pi}{2}\left(\frac{t}{t_{\max }}\right)\right)+j_{2}, \\
& c_{2}=\left(j_{3}-j_{4}\right) * \cos \left(\frac{\pi}{2}\left(\frac{t}{t_{\max }}\right)\right)+j_{4} .
\end{aligned}
$$

In the above formula, $j_{1}, j_{2}, j_{3}$, and $j_{4}$ are the starting and final values of $c_{1}$ and $c_{2}$ respectively. The algorithm is appropriate, when $j_{1}=3.5, j_{2}=0.5, j_{3}=2.5$, and $j_{4}=0.5$ are obtained through many experiments.

2.4. Optimal Number of Cluster Heads. In the performance comparison of fusion control algorithms, clustering can effectively reduce network energy consumption and improve performance. Generally speaking, a wireless sensor network has a large number of nodes, and the energy is limited and cannot directly communicate with the base station. An effective routing protocol is needed. The clustering routing protocol is one of them. It forms a cluster of neighboring nodes and selects out of the cluster head, the nodes in the cluster first transmit the data to the cluster head, and the cluster head merges the data before forwarding it to the next hop or directly to the base station. Assuming that there are $g$ nodes in an $m \times m$ network, the number of cluster heads is $b$, so the probability of a node being elected as a cluster head is $g / b$, the number of nodes distributed in each cluster is $(g / b)-1$, and the number of nodes in each cluster is $(g / b)-1$. In the calculation, the energy consumed by the base station during signal transmission is
$E=\left(\frac{g}{b}-1\right) \times e_{\mathrm{el}} \times l+\frac{g}{b} \times E_{\mathrm{DA}} \times l+\left(E_{\mathrm{el}} \times l+\eta_{\mathrm{am}} \times r_{\mathrm{to}}^{4} \times l\right)$.

In the above formula, $r_{\text {to }}$ is the distance from the cluster head to the base station. When a node transmits data to the cluster head, it consumes a certain amount of energy.

$$
E_{\mathrm{me}}=l \times E_{\mathrm{el}}+l \times \eta_{f} \times r_{\mathrm{to}}^{2} .
$$

In the above formula, $r_{\text {to }}$ is the distance from the node to the cluster head. Assuming that each node is $p(x, y)$, its expectation is

$$
E\left[r_{\mathrm{to}}^{2}\right]=\iint\left(x^{2}+y^{2}\right) p(x, y) \mathrm{d} x \mathrm{~d} y=\iint\left(x^{2}+y^{2}\right) \frac{b}{m^{2}} \mathrm{~d} x \mathrm{~d} y=\frac{m^{2}}{2 b \pi} .
$$

The total energy consumed is

$$
E_{\mathrm{to}}=b E_{\mathrm{CH}}=l \times\left[(2 g-b) \times E_{\mathrm{el}}+\frac{m^{2}}{2 b \pi}(g-b) \eta_{f}+e_{\mathrm{da}} g+b \eta_{\mathrm{am}} r_{\mathrm{to}}^{4}\right] .
$$

Solve the first derivative of $E$ with respect to $b$ and make it equal to zero, so that we can get

$$
\eta_{\mathrm{am}} \times r_{\mathrm{to}}^{4}-\eta_{f} \times \frac{g}{2 \pi} \times \frac{m^{2}}{b^{2}}=0 .
$$

Solve the above equation to get

$$
b=\sqrt{\frac{\eta_{f}}{\eta_{\mathrm{am}}}} \cdot \sqrt{\frac{g}{2 \pi}} \cdot \frac{m}{r_{\mathrm{to}}^{2}}
$$

The decision factor $f_{1}$ is based on the network energy consumption, the decision factor $f_{2} \mathrm{~b}$ is based on the remaining energy of the cluster head, the decision factor $f_{3}$ is based on the distance between the cluster head and the nodes in the cluster, and the decision factor $f_{4}$ is based on the distance between the cluster head and the base station. According to the previous energy consumption model, we can get the total energy consumption of network communication as

$$
E_{\mathrm{to}}=\sum_{g=1}^{g} l \times\left[\left(2\left|c_{b}\right|-1\right) \times E_{\mathrm{el}}+r_{\mathrm{to}}^{2}\left(\left|c_{b}\right|-1\right) \eta_{f}+\left|c_{b}\right| e_{\mathrm{da}}+\eta_{\mathrm{am}} r_{\mathrm{to}}^{4}\right] .
$$

Then, we can get the power consumption judgment factor of the network node as

$$
f_{1}=\frac{1}{g} \sum_{g=1}^{g} l \times\left[\left(2\left|c_{b}\right|-1\right) \times E_{\mathrm{el}}+r_{\mathrm{to}}^{2}\left(\left|c_{b}\right|-1\right) \eta_{f}+\left|c_{b}\right| e_{\mathrm{da}}+\eta_{\mathrm{am}} r_{\mathrm{to}}^{4}\right] .
$$

For the definition of decision factor $f_{2}$, we first sum up the remaining energy of all particle nodes in the algorithm and divide it by the energy of the cluster head. The smaller the value obtained, the greater the probability of being selected as the cluster head and the better. 


$$
f_{2}=\frac{\sum_{i=1}^{g} E}{\sum_{b=1}^{b} e(\mathrm{ch})} .
$$

The definition of decision factor $f_{3}$ is to calculate the maximum average Euclidean distance between a common node and its cluster head according to the node position. The smaller the value, the better the compactness.

$$
f_{3}=\sum_{i=1}^{g} \sum_{b=1}^{b} \frac{d\left(n_{i}, \mathrm{ch}\right)}{\left|C_{P, K}\right|}
$$

$f_{4}$ is the minimum distance between the node and the base station. The smaller the distance from the base station, the lower the communication energy consumption.

$$
f_{4}=\min \left\{d\left(\mathrm{ch}_{i}, \mathrm{bs}\right)\right.
$$

In the above formula, $d\left(\mathrm{ch}_{i}, \mathrm{bs}\right)$ is the distance from the $\mathrm{i}$-th cluster head to the base station. Based on the above four decision factors, the decision function constructed in this article is

$$
\cos t=\beta f_{1}+\alpha f_{2}+\chi f_{3}+\gamma f_{4},
$$

where $f_{1}, f_{2}, f_{3}$, and $f_{4}$ are the decision factors of this algorithm when selecting cluster heads. The specific physical meanings of the four factors are as described above. The four parameters $\alpha, \beta, \lambda$, and $\eta$, respectively, represent the weight of each decision factor in the fitness function. $\alpha, \beta, \gamma, \eta \in[0$, $1]$, and $\alpha+\beta+\lambda+\eta=1$, and the weights of the four decision factors can be adjusted according to actual needs. According to the definition of the fitness function, a relatively small fitness function value can ensure the selection of the optimal cluster head. The smaller the fitness function of the particle, the less the network energy consumption, the more the remaining energy of the cluster head node, the better the compactness within the cluster, and the better the energy consumption of the cluster head communication [21]. Therefore, the goal of improving the particle swarm algorithm is to select the node with the smallest fitness function value as the cluster head, optimize the selection of the cluster head, and reduce network energy consumption.

In the initial stage of the algorithm, each node randomly generates a random number $\mu, 0<\mu<1$, and sets the threshold $T$ for electing cluster heads. $\mu<T$, the node is elected as the candidate cluster head. In the improvement of the threshold $T$, the influence of the global network node is taken into consideration, and comprehensive consideration is given.

Node energy, density, and distance from the base station are three factors.

$$
\begin{gathered}
T(n) \begin{cases}\frac{p}{1-p(d * m i(1 / p))} \cdot \frac{e_{i}}{e_{0}} \cdot \frac{d_{i}-d_{\text {min }}}{d_{\max }-d_{\text {min }}}, & n \in g, \\
0, & n \notin g,\end{cases} \\
Q_{i}=\frac{\text { nei }(i)_{\text {ali }},}{\text { net }_{\text {ali }}}
\end{gathered}
$$

$$
x_{i j}(h+1)=x_{i j}(h)+v_{i j}(h+1) .
$$

In the formula, there is a probability that a network node is elected as a cluster head in normal times, where $p$ is the probability that a network node is elected as a cluster head, $r$ is the number of running rounds of the network at this time, and $G$ is the set of nodes that have been elected as cluster heads in the last $1 / p$ round. $E_{0}$ and $E_{i}$ are the initial energy and current energy of the node, respectively, $d_{\max }$ and $d_{\min }$, respectively, represent the longest and shortest distance between the network node and the sink node, $d$ is the distance between the node and the base station, and $Q_{i}$ is the node density. Nei is the number of neighbor nodes of node $i$, and Net is the number of surviving nodes in the network. The candidate cluster headset is constructed by determining the candidate cluster head. The candidate cluster head only unilaterally determines the energy and location information of the node. It does not take into account the energy consumption of the node and the global network information, and the selection of the algorithm cannot be optimized. It needs to optimize the selection of network candidate cluster heads.

\section{Comparative Experiment Analysis}

3.1. Experimental Design. This study takes the students of two natural classes in grade five of elementary school as the research object, 32 students in one class and 31 students in the second class. Both classes are natural classes. Before the experiment, the author first made a comparative analysis of the students in the two classes. The questionnaire is used to understand the English learning situation of the students in the two classes, the characteristics of the students in the two classes, and the current status of English learning. The pretest is used to understand the students' academic performance; after comparative analysis, it is determined that the two classes are homogeneous, and comparative experimental research can be carried out. The author determines that the first class of the fifth grade is the experimental class, the second class is the control class, and the course taught is the elementary school English listening. The purpose of the experiment is to verify the effectiveness of the flipped classroom teaching model designed by the author. The final purpose of its design is to determine and analyze the changes in the teaching effect under the traditional teaching mode and the flipped classroom teaching mode. The author mainly determines the model from four dimensions and the effectiveness of, that is, whether students have a certain improvement in learning interest, autonomous learning ability, cooperative awareness, and English performance. Through this, the author has made the following experimental hypotheses. (1) The "flipped classroom" teaching model designed by the author for the primary school English listening course can improve the interest of fifth grade students in English listening learning. (2) The "flipped classroom" of the primary school English listening course "teaching mode" can improve students' sense of cooperation. (3) The mobile elementary school English listening "flipped classroom" teaching mode can promote the cultivation of students' 
autonomous learning ability. (4) Students' academic performance after adopting the primary school English listening "flipped classroom" teaching mode has a certain improvement. After the experiment, this study conducted a unified posttest test on the students in the two classes of the experimental class and the control class and compared the learning conditions of the two classes based on the students' posttest results and performed data analysis. We distribute questionnaires, statistically analyze the results of the questionnaires, and conduct interviews with teachers after the experiment to understand and analyze the effects of the flipped classroom model. The duration of the experiment is eight weeks, starting from October 15, 2020, after the midterm exam to 2020 on December $15^{\text {th }}$; a controlled experiment was used to control all irrelevant variables so as not to affect the results of the experiment. Tests and questionnaire surveys were conducted on the experimental class and the control class before and after the experiment, and the results of the experiment were analyzed through statistical data to test the effect of flipped classroom teaching.

By using the flipped classroom model for the experimental group and the control group, a group of students use traditional methods to teach and then compare their subsequent grades to judge the teaching quality of this model. We judge the results of our experiments based on the children's ability to react in class, their enthusiasm in class, and, most importantly, the children's scores in subsequent exams.

3.2. Comparison of Experimental Scores before and after. As shown in Table 3, we can find that after the experiment, the number of students in the high segment of the experimental class increased, the number of failed students decreased, and the scores were more concentrated between 80 and 90 . In the posttest results, the experimental class exam the average score (82.95 points) is higher than the posttest score of the control class (79.9 points). The control class had an excellent rate of $32 \%$ and a passing rate of $86.7 \%$ in the posttest results. Further analysis shows that in the posttest scores of the experimental class, the excellent rate and the passing rate increased respectively. After the test, the scores of the students in the experimental class improved greatly compared with the control class. The overall performance of the students in the experimental class has been a significant improvement [22].

3.3. Video Teaching Survey Results. As shown in Figure 6, we can find that nearly $65.63 \%$ of students are familiar with the teaching method of using animation video to train English listening, and nearly $70 \%$ of students are very willing to use this teaching method to learn, teaching in flipped classrooms. Next, we use more artificial intelligence fusion control algorithms to simplify and help our teaching mode to a certain extent. We will find that students think that the video explanation on the panoramic classroom platform is very interesting, and when they encounter problems, they can seek others with the help of classmates and teachers, or watching the video again, learning does not feel boring. This data also proves that the flipped classroom model of the artificial intelligence fusion control algorithm adopted in this case study has been liked and recognized by the students.

The students will be divided into several groups through video learning, communicate between the front and back tables, and describe the English they have heard. The teacher will go to each group to understand the cooperation and exploration between each group, give corresponding suggestions and guide the students according to the students' communication between each group, and encourage students with strong ability to become small teachers, so that teachers can spend more time helping students with less strong ability [23]. The discussion among students is shown in Figure 7.

\section{Discussion of Experimental Results}

4.1. Student Interest Survey. As shown in Figure 8, it can be seen that $40.63 \%$ of the students like and adapt to the learning method based on watching animation videos, $43.75 \%$ of the students feel that time passes quickly when taking English classes, and 56.25\% of the students think that taking English classes is a happy thing. Generally speaking, students' interest in learning is relatively high, but there are also some students who feel that English has been in class for a long time, and their interest in learning needs to be improved. The author reflects on the preparation of learning resources before class, and full consideration should be given to them. Learner's characteristics, design intuitive, and vivid tasks that can arouse students' interest [24] should be taken into consideration.

4.2. Awareness of Cooperation among Students. Students' sense of cooperation is shown in Figure 9: it can be drawn from the data that $50 \%$ of the students like group discussion and are willing to participate in group activities, $56.25 \%$ of the students like to finish the homework with classmates, flip group discussion in class makes learning boring, and the group activities in class also meet the needs of the students and let them discuss themselves and show the results. It cultivates students' sense of unity and cooperation [25].

4.3. Student's Learning Effect. Figure 10 shows the student's learning effect: the author mainly examines whether the students have improved their English listening in the flipped classroom, whether watching the animation video-based learning method is helpful for learning, whether the English listening has improved, and whether the listening questions are wrong. It is less than before and whether learners can well grasp the relevant knowledge of preclass learning to investigate the learning effect of students. Through data analysis, more than $50 \%$ of students meet the expressions of the above questions, and self-learning before class satisfies the students' personalities. The learning effect has been improved to a certain degree [26]. 
TABLE 3: Students' performance before and after the experiment.

\begin{tabular}{lccccc}
\hline & Class & $N$ & Average & Standard deviation & Mean standard error \\
\hline Pretest results & Experimental class & 32 & 78.8 & 13.5 & 2.33 \\
& Control class & 31 & 78.1 & 13.2 & 2.45 \\
\hline Posttest results & Experimental class & 32 & 82.95 & 12.1 & 2.1 \\
& Control class & 31 & 79.9 & 13.6 & 2.5 \\
\hline
\end{tabular}

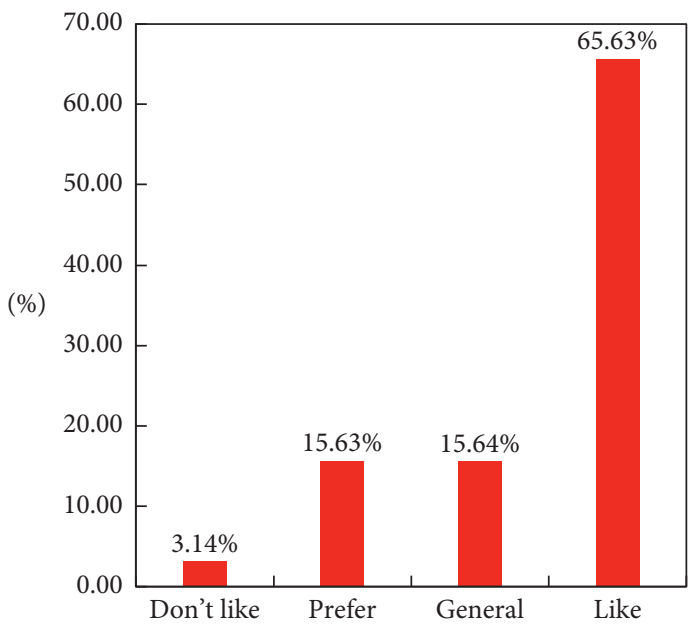

(a)

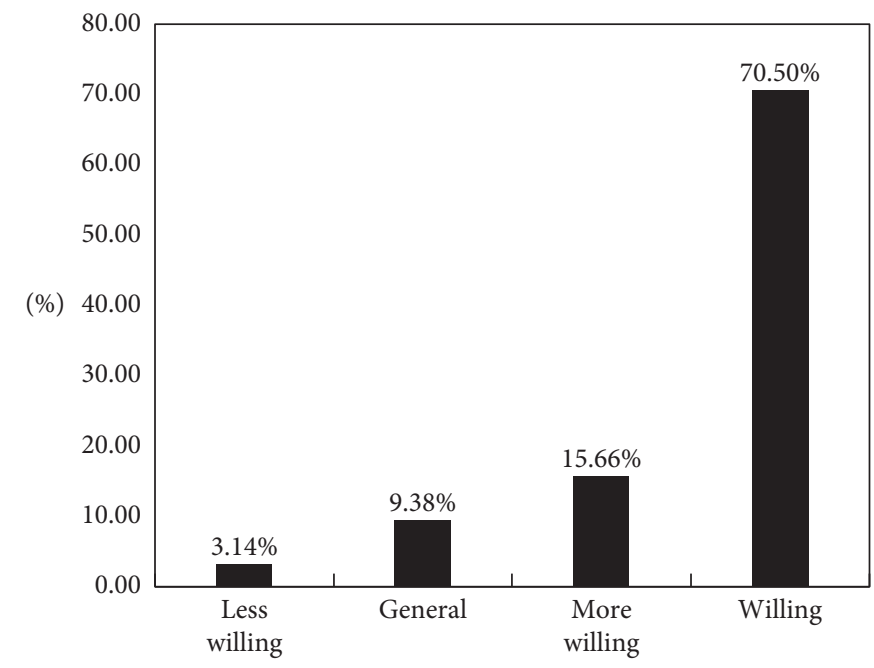

(b)

FIgURE 6: Survey of English listening learning. (a) How many students like to learn English listening with animated videos. (b) Whether students accept their own use of animated videos for learning.

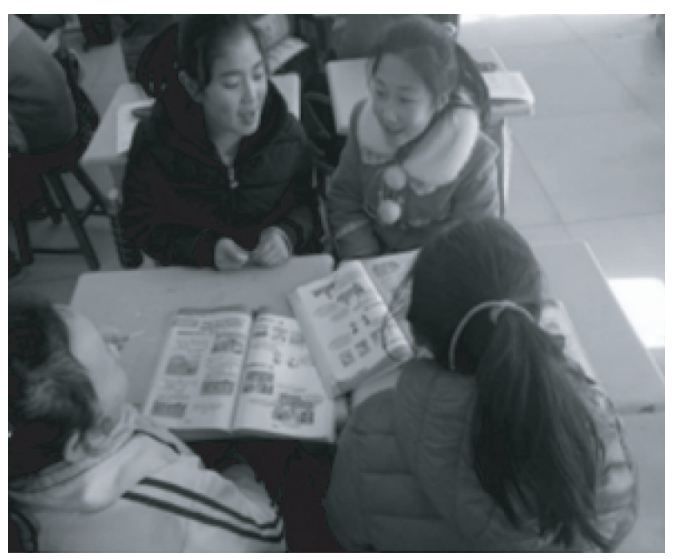

(a)

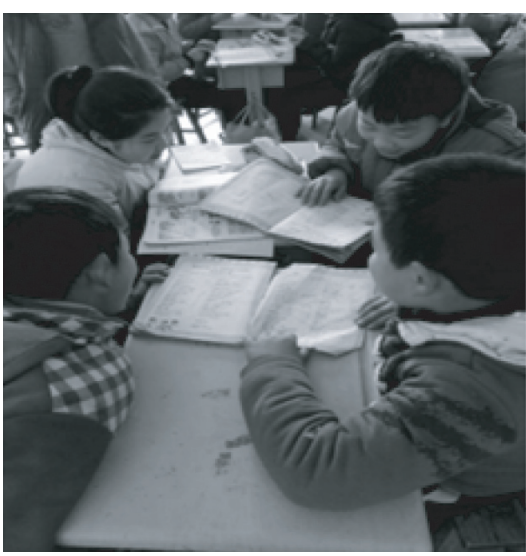

(b)

Figure 7: Group discussion. 


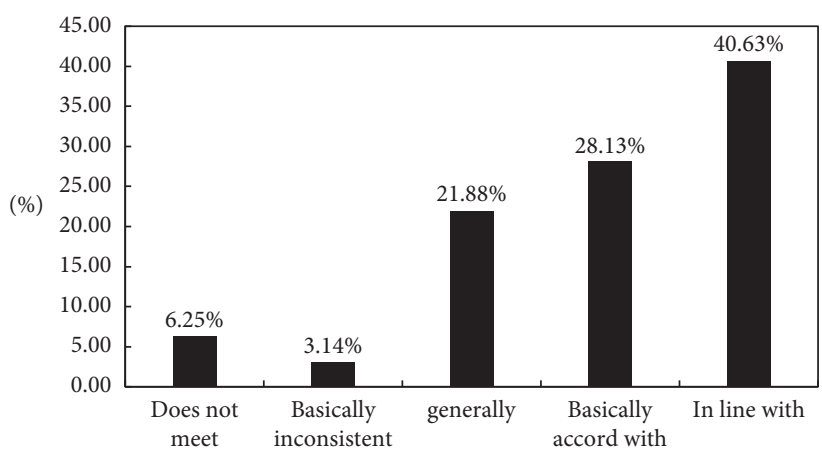

(a)

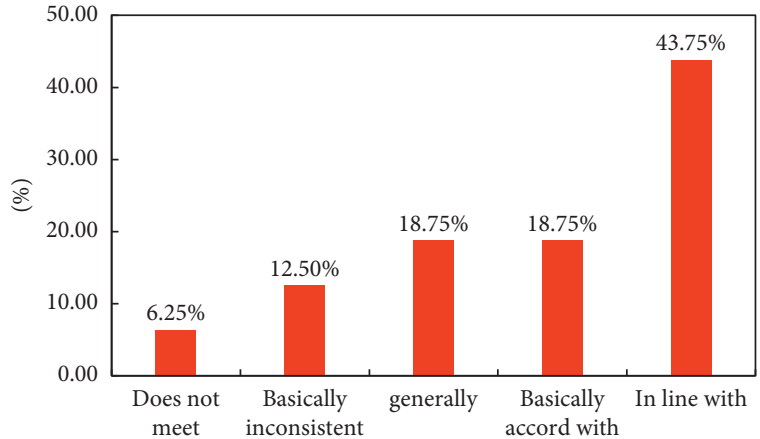

(b)

Figure 8: Students' self-consciousness results. (a) The degree of video learning. (b) Active learning after class.

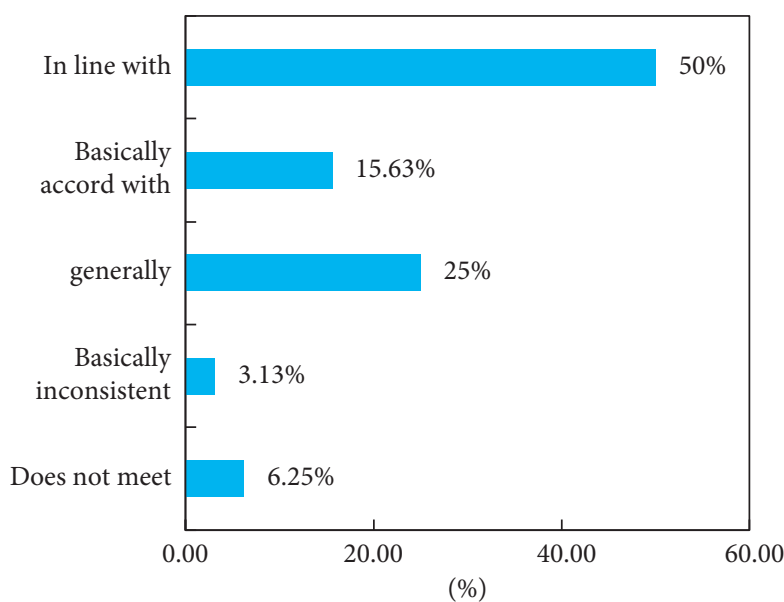

(a)

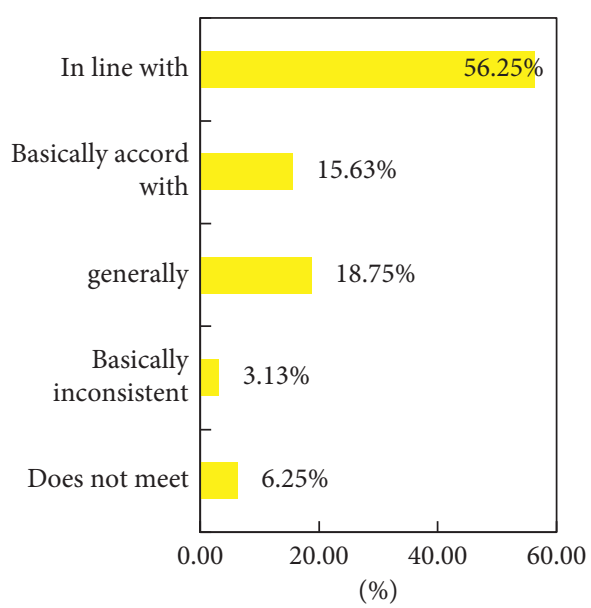

(b)

Figure 9: The popularity of collaborative inquiry discussions among students. (a) Group discussion and participation. (b) Teamwork in learning.

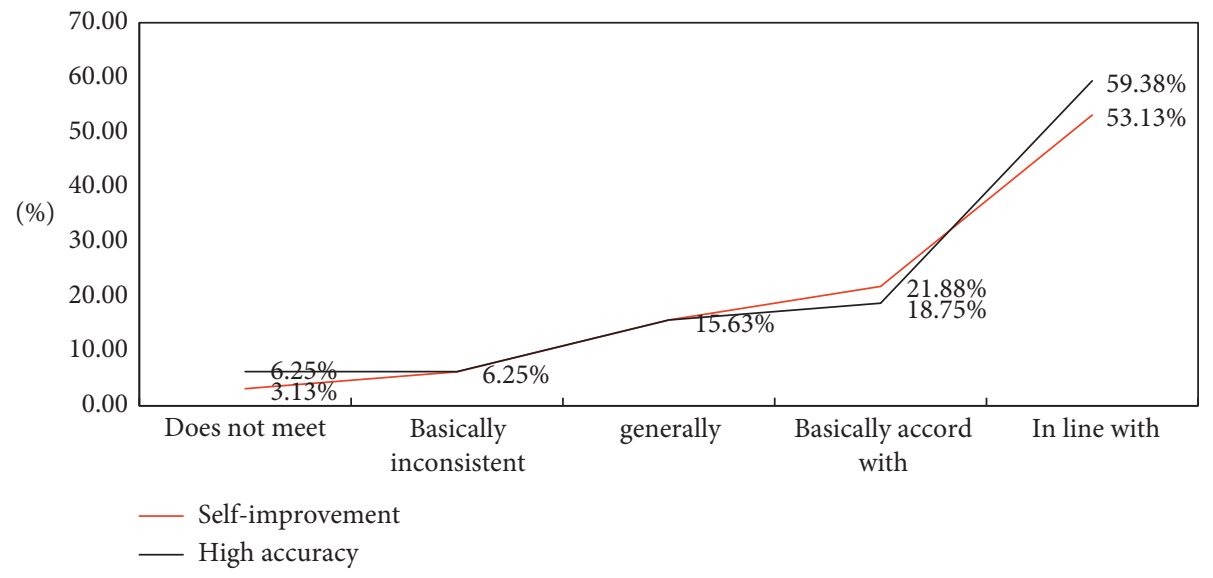

(a)

Figure 10: Continued. 


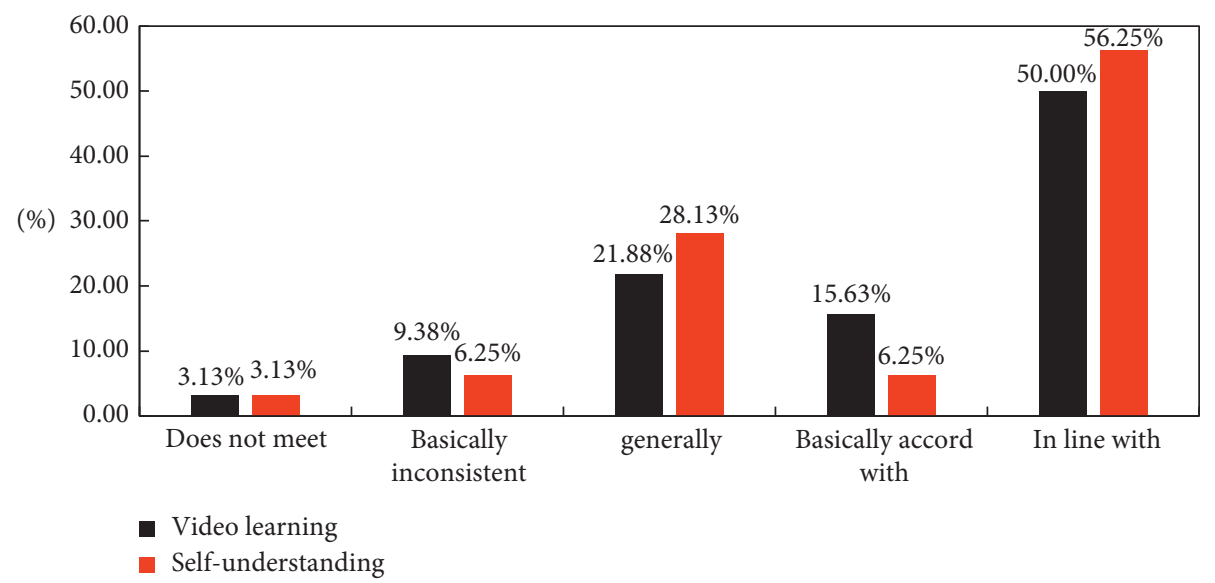

(b)

FIgURE 10: Improved learning effect. (a) Self-perception improvement. (b) Improvement in learning style.

\section{Conclusions}

Updating the education model is not only an inevitable trend in the development of Internet information technology but also an important way to promote the deepening of the reform and development of higher education. The artificial intelligence fusion control algorithm makes the flipped classroom more intelligent, helps them provide a more lively and interesting classroom, can enhance their interest in learning, and then improve the students' English performance. However, the transformation model of classroom teaching not only responds to China's education informatization but also responds to the concept of China's English curriculum reform. Educational circles all over the world have been widely observed. Advantages: the prosperous development of large-scale open network projects today provides a valuable opportunity to effectively transform the classroom teaching mode of the English academy. Therefore, the application of the flipped teaching model in English practice can point out a new development direction for the implementation of the two main stages of college English information knowledge introduction and knowledge internalization. It also has important practical significance to make up for the shortcomings of the traditional teaching model and actively respond to various challenges and threats in the teaching process to try to change the teaching mode of classroom teaching. With the wave of informatization teaching reform, classroom reform is imperative. They need to learn, improve, and participate in resale teaching. Aiming at the actual situation of each education subject, classroom teaching methods are used to promote the best development of classroom teaching. Practical results have proved that this method of teaching is scientific and feasible. The design and implementation of this model have improved students' learning interest, autonomous learning ability, cooperative awareness, and learning results to a certain extent. This study cannot improve students' self-learning before class. Based on the existing educational environment, it is currently only possible to control the time for students to study independently and the completion of preclass homework. The article uses artificial intelligence fusion control algorithms to make flipped classrooms more intelligent, helping them provide more vivid and interesting classrooms, and improving their academic performance through this way. In the future life, the intelligence of artificial intelligence algorithms will be more and more optimized. Later, classroom teaching will become more diversified and more efficient.

\section{Data Availability}

The data that support the findings of this study are available from the corresponding author upon reasonable request.

\section{Conflicts of Interest}

The author declares no potential conflicts of interest with respect to the research, authorship, and/or publication of this article.

\section{References}

[1] X. Yang, H. Li, L. Ni, and T. Li, "Application of artificial intelligence in precision marketing," Journal of Organizational and End User Computing, vol. 33, no. 4, 2021.

[2] L. Liu, "Research on IT English flipped classroom teaching model based on SPOC," Scientific Programming, vol. 2021, Article ID 7273981, 9 pages, 2021.

[3] Y. Jia, "Research on the practice of college English classroom teaching based on Internet and artificial intelligence," Journal of Intelligent and Fuzzy Systems, vol. 42, no. 1, pp. 1-10, 2021.

[4] H. Bicen and M. Beheshti, "Assessing perceptions and evaluating achievements of ESL students with the usage of infographics in a flipped classroom learning environment," Interactive Learning Environments, vol. 3, pp. 1-29, 2019.

[5] L.-L. Chen, "Impacts of flipped classroom in high school health education," Journal of Educational Technology Systems, vol. 44, no. 4, pp. 411-420, 2016. 
[6] M. Chan, C. Chun, H. Fung, J. H.M. Lee, and P. J. Stuckey, "Teaching constraint programming using fable-based learning," Proceedings of the AAAI Conference on Artificial Intelligence, vol. 34, no. 9, pp. 13366-13373, 2020.

[7] T. Feng, "Research on teaching model of MOOC-based College English flipped classroom," Boletin Tecnico/Technical Bulletin, vol. 55, no. 20, pp. 503-508, 2017.

[8] L. Yu and N. Peng, "Research on English teaching reform based on artificial intelligence matching model," Journal of Intelligent and Fuzzy Systems, vol. 42, no. 1, pp. 1-10, 2021.

[9] S. Zhou and T. Zhang, "Research on the construction of flipped classroom model for English teaching based on SPOC," Revista de la Facultad de Ingenieria, vol. 32, no. 14, pp. 267-273, 2017.

[10] Y. V. Prokop, O. G. Trofymenko, and O. Dykyi, "Research of approaches to teaching the course "algorithms and data structures” for computer science students," Scientific notes of Taurida National V.I. Vernadsky University. Series: Technical Sciences, vol. 1, no. 2, pp. 216-220, 2021.

[11] R. Kanniga Devi, M. Gurusamy, and P. Vijayakumar, "An efficient cloud data center allocation to the source of requests," Journal of Organizational and End User Computing, vol. 32, no. 3, 2020.

[12] J. Lu, L. Feng, J. Yang, M. M. Hassan, A. Alelaiwi, and I. Humar, "Artificial agent: the fusion of artificial intelligence and a mobile agent for energy-efficient traffic control in wireless sensor networks," Future Generation Computer Systems, vol. 95, pp. 45-51, 2019.

[13] Z. Zhao, Q. Xu, and M. Jia, "Sensor network optimization of gearbox based on dependence matrix and improved discrete shuffled frog leaping algorithm," Natural Computing, vol. 15, no. 4, pp. 653-664, 2016.

[14] J. Lin, "Artificial intelligence control algorithm for steering motion of wheeled soccer robot," Journal of Intelligent and Fuzzy Systems, vol. 38, no. 2, pp. 1-9, 2020.

[15] W. Xu, W. Xiong, Z. Shao, and Y. Li, "Analysis of effectiveness and performance prediction of sports flipped classroom teaching based on neural networks," Scientific Programming, vol. 2021, Article ID 5284457, 7 pages, 2021.

[16] T. Ribeirinha and B. D. D. Silva, "The flipped classroom model potential in online learning: an assessment focused on pedagogical interactions," Publicaciones, vol. 51, no. 3, pp. 321-345, 2021.

[17] E. Blair, C. Maharaj, and S. Primus, "Performance and perception in the flipped classroom," Education and Information Technologies, vol. 21, no. 6, pp. 1465-1482, 2016.

[18] C. Nwosisi, A. Ferreira, A. Ferreira, W. Rosenberg, and K. Walsh, "A study of the flipped classroom and its effectiveness in flipping thirty percent of the course content," International Journal of Information and Education Technology, vol. 6, no. 5, pp. 348-351, 2016.

[19] W. J. Zuber, "The flipped classroom, a review of the literature," Industrial \& Commercial Training, vol. 48, no. 2, pp. 97-103, 2016.

[20] B. Sohrabi and H. Iraj, "Implementing flipped classroom using digital media: a comparison of two demographically different groups perceptions," Computers in Human Behavior, vol. 60, pp. 514-524, 2016.

[21] G. Asiksoy and F. Zdamli, "Flipped classroom adapted to the ARCS model of motivation and applied to a physics course," Eurasia Journal of Mathematics, Science and Technology Education, vol. 12, no. 6, pp. 1589-1603, 2016.

[22] T. Long, J. Logan, and M. Waugh, "Students' perceptions of the value of using videos as a pre-class learning experience in the flipped classroom," TechTrends, vol. 60, no. 3, pp. 245-252, 2016.

[23] K. I. Cotta, S. Shah, M. M. Almgren, L. Z. Macías-Moriarity, and V. Mody, "Effectiveness of flipped classroom instructional model in teaching pharmaceutical calculations," Currents in Pharmacy Teaching and Learning, vol. 8, no. 5, pp. 646-653, 2016.

[24] L. R. DeRuisseau, "The flipped classroom allows for more class time devoted to critical thinking," Advances in Physiology Education, vol. 40, no. 4, pp. 522-528, 2016.

[25] J. Hanson, "Surveying the experiences and perceptions of undergraduate nursing students of a flipped classroom approach to increase understanding of drug science and its application to clinical practice," Nurse Education in Practice, vol. 16, no. 1, pp. 79-85, 2016.

[26] W.-K. Liou, K. K. Bhagat, and C.-Y. Chang, "Beyond the flipped classroom: a highly interactive cloud-classroom (HIC) embedded into basic materials science courses," Journal of Science Education and Technology, vol. 25, no. 3, pp. 460-473, 2016. 